\title{
Tiempo y relato en los testimonios de activistas del movimiento de DDHH en Argentina
}

Rubén Isidoro Kotler

Archivo Histórico-FFyL-UNT/ RELAHO / rubenk074200o@yahoo.com.ar

Fecha de recepción: 1/9/2018. Fecha de aceptación: 7/2/2019.

\begin{abstract}
Resumen
Los debates en torno a la historia oral no han cejado en los últimos años a pesar de haber alcanzado cierta madurez en su faz metodológica. Algunos aspectos referidos a la ética profesional, a la veracidad de los testimonios, a la forma de "hacer" historia oral y a la propiedad de los relatos, siguen siendo materia de debate en cada congreso de historia oral. Uno de los aspectos que aún precisan ser debatidos en profundidad es el tiempo de los testimonios, resultante de las entrevistas de historia oral con protagonistas de la historia reciente. Dentro de la última problemática mencionada la reflexión sobre "el protagonismo de los protagonistas" de la historia al narrar sus memorias nos permitirá re-pensar el valor del testimonio oral en cuanto que devuelve al actor social a un pasado vivido que entronca con el presente de la entrevista. En el caso de la entrevista a militantes del movimiento de derechos humanos podemos pensar en un triple protagonismo de los actores sociales que los sitúa en todo momento en un terreno que abarca pasado y presente: 1) El protagonismo inicial de una militancia que comienza bien en los años duros de la última dictadura cívico militar en la búsqueda de los familiares detenidos - desaparecidos o en los primeros años de la transición; 2) El protagonismo que adquieren nuevamente al relatar la experiencia de vida en las entrevistas de historia oral, donde la construcción del relato histórico solo es posible en quiénes han vivido la historia y han sido testigos directos de ella; 3) La participación como testigos / querellantes en los juicios de lesa humanidad de los últimos años y que vuelve a colocar a los militantes del movimiento de DDHH como partícipes de un hecho histórico relevante. Me propongo entonces en el presente artículo, examinar la cuestión temporal y el triple protagonismo mencionado con el objetivo de aportar al campo de estudio nuevas cuestiones sobre las que pensar a la hora de utilizar la compleja metodología que nos propone el campo de la historia oral.
\end{abstract}

\section{Time and Narration in the testimonies given by Argentine Human Rights movements' activists}

Debates around Oral History have not ceased for the last years, in spite of having reached certain maturity in their methodological face. Some aspects which refer to

\section{Palabras clave}

Derechos humanos tiempo narración
Keywords

Human Rights time narration 
professional ethics, to the truthfulness of testimonies, to the way in which oral history is produced and to the property of the historical accounts, still remain object of debate in every Oral History Convention. One of the issues which still needs to be deeply discussed is the time of the testimonies, as a result of the oral history interviews with the protagonists of recent history. Within the last problem referred to as a reflection on "history protagonists" protagonism" when narrating their memories, we will be able to reconsider the significance of oral testimony as it makes the social actor return to a vivid past which is related to the present of the interview. When it comes to interviewing human rights movements'activists, we can think of a triple protagonism of the social actors, placing them in a permanent position which covers both past and present: 1) That initial protagonism of political activism which begins in the hard years of the last civic-military dictatorship or during the transition to democracy with the search for their disappeared relatives. 2 . That protagonism they achieve one more time when they narrate their life experience during the oral history interviews, where building up the historical accounts can only be carried out by those who have experienced history and who have been their direct witnesses. 3 . The participation as witnesses/claimants in the trials for crimes against humanity of the last years which, once again, turns Human Rights activists into main characters in a relevant historical deed. In this article, I thus aim at examining the temporal matter and the triple protagonism mentioned above, so as to contribute to the study field with new issues to think about when it comes to using that complex methodology proposed by oral history.

\section{Introducción}

El trabajo que presento surge de las reflexiones posteriores a la edición de mi libro sobre la historia del movimiento de Derechos Humanos de la provincia de Tucumán (Kotler, 2018) y como producto de la tesis doctoral defendida en 2013 en la Universidad de Salamanca sobre la misma temática. En el contexto del desarrollo de los juicios por delitos de lesa humanidad en la provincia norteña, el registro testimonial y la presencia de viejos militantes del campo de los derechos humanos, me llevó a pensar en ellos como activos actores sociales y no como meros testimoniantes de un pasado remoto. Según Josefina Cuesta "el historiador faltaría a su tarea si, subyugado por las fuentes orales, sucumbiera a las sirenas de la memoria de otros y cayera en las trampas de la subjetividad. Pero se privaría de un inmenso campo de investigación si se limitara a la estrecha regla de la crítica histórica positivista y rehusara invertir la perspectiva desde un punto de vista hermenéutico: recoger, utilizar e interpretar lo que parece sospechoso en la memoria para contribuir a una historia objetiva de la subjetividad" (Cuesta, 2008: 122). Por su parte, el historiador británico Eric Hobsbawm afirmaba que cuando comenzó su carrera como joven historiador entrevistando a sobrevivientes de la Fabian Society previo a 1914, preguntándoles cuestiones sobre su tiempo, la primera lección que aprendió fue "que ni siquiera valía la pena entrevistarles a menos que averiguase más cosas sobre el tema de la entrevista de las que ellos podían recordar. La segunda lección fue que en lo referente a cualquier hecho que pudiera verificarse de modo independiente, la memoria tendía a fallarles. La tercera lección fue que era inútil tratar de hacerles cambiar sus ideas, ya que éstas se habían formado hacía mucho tiempo y ya eran fijas. (...) Los últimos 30040 años han sido la era más revolucionaria de la historia documentada. Nunca antes el mundo, esto es, las vidas de los hombres y las mujeres que viven en la tierra, se ha visto transformado de modo tan profundo, dramático y extraordinario en un período tan breve. Captar intuitivamente este hecho resulta difícil para las generaciones que no han visto como era antes el mundo" ${ }^{1}$. Aunque concuerdo con la segunda y tercera lección que nos entrega el historiador inglés, no estoy de acuerdo con la primera. La experiencia de quienes trabajamos con fuentes orales nos indica que aún sin conocer 
profundamente el pasado que se busca desentrañar en las entrevistas, no sólo no es inútil hacerlas, sino que sirven de necesario primer paso en el camino de indagar qué ha sucedido, cómo ha sido posible y qué percepción tienen los actores sociales de aquello. Concuerdo que a veces la memoria de los entrevistados falla -ya lo recordaba Tucídices- pero aun así estimo, según mi propia experiencia, que recoger el testimonio de esos actores que han tenido una participación en el pasado se hace fundamental para captar cómo han vivido el suceso, sus puntos de vista y sus análisis, no solo de lo ocurrido, sino también de lo que quisieron que ocurriera. Es así que me parece válida la metodología que nos aporta la historia oral para el estudio de la historia reciente, en mi caso del movimiento de derechos humanos argentino.

En mi caso tuve una desventaja respecto al planteo de Hobsbawm pues no he vivido de igual manera el pasado reciente que he buscado desentrañar como lo han hecho los actores sociales que he entrevistado; sin embargo, lo cierto es que parte de la vida de estos grupos han sido para mí reconocibles por ser contemporáneo de ellos, una ventaja que nos permite, sin lugar a dudas, la historia del tiempo presente.

\section{Dominick LaCapra sostiene que}

el testimonio de los sobrevivientes, incluido el proceso mismo de las entrevistas, es en cierta manera un género nuevo que se está haciendo, necesariamente problemático, que tiene consecuencias en la historia oral, especialmente en las áreas de investigación más delicadas. Los historiadores todavía no han elaborado una manera aceptable de "usar" los testimonios, y las profundas diferencias entre el estado y la experiencia de las distintas víctimas, así como entre las diversas respuestas que suscitan no hacen más que complicar su tarea (LaCapra, 2005: 126-127). ${ }^{2}$

En el proceso de construcción del relato, la experiencia de los actores participantes, siempre desde un plano subjetivo, suma al dato empírico una realidad que la historiografía tradicional suele descuidar, como ser las estructuras del sentir (Williams, 2009) de quienes tuvieron un rol protagónico determinado. Según Paul Thompson "la historia oral devuelve la historia a la gente con sus propias palabras. $Y$ al ofrecer un pasado, también ayuda a encontrar un futuro de elaboración propia (...) le da vida a la propia historia, ampliando así su enfoque. Habla de personajes no sólo extraídos entre los líderes, sino también entre la mayoría desconocida de la gente" (Thompson, 1998). ${ }^{3}$

Por su parte Rosa García Orellán reafirma que "los relatos de vida o historias de vida son subjetivos. No es la labor de la persona investigadora perseguir la verdad de dichos relatos, sino penetrar en el entramado de los mismos, donde se construyen y reconstruyen las relaciones sociales y, en definitiva, la cultura que está emergiendo a través de la incorporación de experiencias, que la persona muestra en su relato" (García Orellán, 2012: 77). Y esa ha sido mi búsqueda en la investigación sobre la historia del movimiento de derechos humanos de Tucumán, resultado de la investigación que derivó en mi tesis doctoral primero y en la publicación de mi libro después (Kotler, 2018), donde surgen las reflexiones que siguen.

\section{El triple protagonismo de los activistas}

La entrevista de historia oral referida a procesos de la llamada historia reciente o historia del tiempo presente, se enmarca siempre en el presente y está atravesada por una triple conjunción: el presente de los entrevistados, el presente del entrevistador y el del tema de la pesquisa, la cual, inevitablemente, está atravesada por esta lógica temporal. ${ }^{4}$ Los actores sociales entrevistados ya como víctimas, ya como sobrevivientes, ya como familiares de víctimas, hablan desde el presente que les toca vivir con toda la carga emocional
2. Si bien es cierto que todavía no hay un acuerdo acabado sobre el "cómo hacer" historia oral, los últimos encuentros académicos internacionales han fijado unas pautas a partir de la recepción de trabajos evaluados y por consensos claramente establecidos sobre "qué es historia oral". En este sentido es posible afirmar que la mera recolección de entrevistas no supone a priori "hacer historia oral" y por el contrario la práctica va más allá del acto de entrevistar sujetos participantes. En este sentido el método historiográfico no difiere del todo cuando incorporamos a los trabajos de investigación histórica fuentes menos tradicionales como las fuentes orales, entre otras.

3. Véase también Cuesta, 2008.
4. En el caso del movimiento de derechos humanos toda narración sobre la resistencia a la dictadura y a la búsqueda de verdad y justicia estuvo en los últimos años atravesada por el desarrollo de los juicios de lesa humanidad de los primeros años del 2000. 
tanto de la historia personal que les franquea, como la misma historia del presente en el que viven y en el que, sin lugar a dudas, cifran sus esperanzas o recuestan sus decepciones. Además para el caso de los militantes del campo de los DDHH en el caso tucumano, la realidad de los juicios inaugurados en 2008 y los hallazgos con su posterior identificación de cuerpos de represaliados tanto en el Pozo de Vargas como en el Arsenal Miguel de Azcuénaga, implicó una complejidad por saberse aún dentro del proceso histórico por cuanto comenzaron, en algunos casos, a ver cumplidos sus objetivos de saber qué había ocurrido con sus familiares desaparecidos por un lado y de ver, aun con limitaciones, un avance en la concreción de la demanda de justicia.

Para Armando Camarena y Gerardo Necoechea,

la historia oral debe rescatar la historicidad de los testimonios. El tiempo es la clave de ese sentido histórico. Corresponde al historiador rescatar el tiempo, introducirlo en la entrevista, y esto es precisamente lo que distingue su labor de otras disciplinas (...) El análisis del tiempo no se propone únicamente reconstruir el pasado, aunque esto sea esencial; intenta estudiar cómo se transforma la vida de la gente y cómo ésta narra tales transformaciones (Camarena y Necoechea, 2008: 55).

Claramente el tiempo de la entrevista es distinto al tiempo de la narración, sin embargo ambos deben conjugarse en la compleja trama que se procura reconstruir. Lo que complejiza aún más el trabajo con fuentes orales en temas de investigación donde los actores sociales entrevistados siguen militando y sus actuaciones siguen impactando en el presente, como es el caso del movimiento de DDHH, es el triple protagonismo que atraviesa al testimoniante:

1) El protagonismo inicial de una militancia que comienza bien en los años duros de la última dictadura cívico militar en la búsqueda de los familiares detenidos - desaparecidos o en los primeros años de la transición;

2) El protagonismo que adquieren nuevamente al relatar la experiencia de vida en las entrevistas de historia oral, donde la construcción del relato histórico solo es posible en quienes han vivido la historia y han sido testigos directos de ella;

3) La participación como testigos / querellantes en los juicios de lesa humanidad de los últimos años vuelve a colocar a los militantes del movimiento de DDHH como partícipes de un hecho histórico relevante. La participación en los juicios los tiene, en la mayoría de los casos, como testimoniantes ante los tribunales federales.

Al hablar de los cambios sociales, Williams explicaba que podían ser de dos maneras: por una parte son cambios de "presencia" y por la otra, "no necesitan esperar una definición, una clasificación o una racionalización antes de ejercer presiones palpables y de establecer límites efectivos sobre la experiencia y sobre la acción". Según Williams, tales cambios pueden ser definidos como cambios en la "estructura del sentir", por lo tanto, debemos procurar establecer "los significados y valores tal como son vividos y sentidos activamente; y las relaciones existentes entre ellos y las creencias sistemáticas o formales" (Williams, 2009: 154). Una alternativa a las estructuras de sentimiento, sería el de las estructuras de la experiencia. Al definir los elementos del testimonio como una estructura, los podemos observar entonces como "un grupo de relaciones internas específicas, entrelazadas y a la vez en tensión". La tensión en el caso en estudio se plantea desde ese triple protagonismo que al mismo tiempo implica a los relatos testimoniales. Como señala Williams, "estamos definiendo aquí una experiencia social que todavía se encuentra en proceso, que no siempre es reconocida como social, sino como privada" (2009: 154). 
Buscamos por medio de las entrevistas examinar no sólo qué ha ocurrido y cómo ha sido posible el surgimiento de estos grupos sociales, sino también qué percepción tienen o han tenido sus militantes ${ }^{5}$ de lo ocurrido, qué quisieron que ocurriera y qué fue lo que realmente ocurrió. Es así como Alessandro Portelli entiende la práctica de la historia oral al asegurar que "no solo nos habla de lo sucedido, sino además acerca de lo que la gente quiso que ocurriera, lo que creía que estaba ocurriendo y lo que realmente ocurrió" (Portelli, 1991). La particularidad de trabajos históricos donde los actores sociales continúan estando en el "centralidad de la escena" la correlación entre lo que sucedió / sucede y lo que "quisieron que suceda / sucede" se desplaza al presente mismo, es decir que todavía hablamos de historia presente. Se indagan las pautas de la experiencia vivida narrada en tiempo presente sobre un pasado que también es presente. Camarena y Necoechea afirman que "aunque el tiempo siempre está en presente en el acontecer cotidiano, no es un elemento consciente en el curso de la entrevista, ni para el estudioso ni para quien cuenta su vida". Sin embargo, afirman que "la forma en que se maneja el tiempo revela la concepción que de éste tienen ambos protagonistas" (Camarena y Necoechea, 2008). Si bien pueden tanto entrevistados como entrevistadores no ser conscientes de tal devenir del tiempo se hace necesario reflexionar sobre ello al momento de la transcripción e interpretación de los relatos.

\section{Componentes esenciales del testimonio y sus complementos}

Josefina Cuesta afirma que la entrevista "es fruto de la superposición y combinación de las diferentes memorias, de las que el sujeto es portador: la memoria personal, social, colectiva y dentro de ésta (...) la familiar, de clase, nacional, política o ideológica" (Cuesta, 2008: 128). Esto también suena a verdad de Perogrullo, sin embargo, merece especial atención porque a esta lógica de transversalidad de la memoria se suma la temporalidad mencionada anteriormente. Resulta entonces importante aquí mencionar lo que para Paul Ricoeur y Renaud Dulong (Cuesta, 2008) son los componentes esenciales del testimonio pero que en función de todo lo mencionado deben re-significarse:

"De la aseveración del hecho a la certificación de su autenticidad: 'Yo estaba allí'”

Este componente es fácilmente ubicable en los testimonios. Por lo general, encontramos que la mayoría de los relatos utilizan la primera persona, bien del singular, cuando narran una acción individual, o bien del plural, cuando se posicionan dentro de una acción acometida por la organización a la que pertenecían (o pertenecen). La mayoría refiere a hechos concretos de sus vivencias personales. Sucede, incluso, que algunos entrevistados han resguardado consigo una carpeta con documentos personales entre los que se destacan recortes de prensa de la época y van rememorando, a la par que muestran el "documento" donde aparece el registro, que, efectivamente, ellos han sido partícipes, ya porque se los menciona, ya porque aparecen en la fotografía que acompaña a la nota periodística. Estos archivos resultan al mismo tiempo como los soportes materiales de la memoria como los denomina Hugo Vezzetti (2001), pues en concreto una fecha o un lugar termina de precisar el "yo estaba allí" y permite dar mayor veracidad al propio testimonio al tiempo que califica al testimoniante como "válido", pues quién mejor que él, que ha estado allí, para certificarlo.

A este primer componente le corresponde su complemento: Yo estoy aquí, por cuanto no se trata sólo de una militancia pasada sino de una militancia presente. El hecho de no haber abandonado la búsqueda de verdad y justicia convierte al militante del campo de los derechos humanos en un sujeto histórico que no solo narra su experiencia pasada sino que testimonia su experiencia presente. No sólo ha sido testigo de un hecho pasado, sino que además, es testigo privilegiado de un hecho presente vinculado a ese pasado.
5. Hablo de testigos como los entiende Jelín en una de las acepciones en el campo de la historia oral: aquellas personas que han vivido una experiencia y pueden en un momento posterior narrarla, "dar testimonio" (Carnovale, Lorenz y Pittaluga, 2006). 
6. En los términos expuestos por Josefina Cuesta tomados de Dulong.

\section{"La especificidad del testimonio: 'Yo lo vi"”}

El haber estado o el haber sido "testigo ocular" " hacen que necesariamente el relato pase por la prueba de la comprobación y la aseveración. Esa primera persona se transforma en singular cuando lo individual supera lo colectivo. Igualmente todo relato en primera persona supone la existencia del testigo ocular ya que el haber estado en un determinado hecho o haber sido partícipe del mismo, convalida el conjunto del relato más allá de las contradicciones internas del mismo, incluso más allá de ciertas omisiones o equivocaciones. El testimoniante se ubica inmediatamente en el lugar de la acción y transmite, lo más fielmente que puede, no solo lo que ha visto, sino su propia experiencia subjetivada, claro está, en la acción de la que ha sido partícipe.

A este componente se complementa el Yo lo sigo viendo, lo sigo viviendo, por cuanto la militancia que se perpetúa en el tiempo tiene sus consecuencias presentes en los juicios. No sólo son testigos de un pasado remoto sino que son testigos - querellantes - de un juicio presente. La palabra autorizada se renueva no solo en la actuación pasada sino en las actuaciones presentes que se ven entonces reforzadas.

\section{"La autodesignación y acreditación: 'Puedes creerme".}

Este componente no suele hacerse explícito en los testimonios, pues toda entrevista es, por lo general, buscada por el historiador y "pautada" entre las dos partes. La concreción del encuentro suele estar signada por el principio de credibilidad de la fuente más también en cierto principio de incertidumbre y duda. De todas formas, hay que tener presente que siempre que el entrevistado narra un suceso en particular busca la apoyatura material para que el relato, que podría ser "no creíble", se torne veraz. Los soportes materiales de la memoria, a los que hacíamos mención más arriba se vuelven imprescindibles cuando el relato aparece increíble.

Atravesados por la lógica judicial el puedes creerme se complementa con La justicia me ha creído, pues producto de sus testimonios judiciales se han comprobado hechos o se ha dictado sentencia. Por lo tanto, el relato no es solo motivo de credibilidad histórica sino de credibilidad judicial. Nuevamente el doble principio de verdad y justicia se ponen en juego entre el testimonio judicial y el testimonio de historia oral.

\section{"Ante la posibilidad de la sospecha, confrontación de testimonios: 'Pregunta a otros""}

Cuando la auto-acreditación planteada en el punto anterior es puesta en duda, asoma en el entrevistado la confrontación con sus pares. Al preguntar a otros o al apoyarse en la posibilidad de la verificación sobre el dato de un lugar o una fecha que no se recuerda, los entrevistados, salvo excepciones, presumen la posibilidad de que el entrevistador pueda preguntar a "otros testigos". Vale aquí el ejemplo de una de las entrevistadas que había puesto como condición para dar su testimonio, hacerlo con un par que corroborara o contrastara su testimonio.

Como complemento de este componente el testimonio histórico se apoya en el testimonio judicial, La justicia ha preguntado a otros (y lo ha confirmado). Desde ya que el principio del testimonio judicial es distinto al del testimonio histórico, sin embargo, uno puede apoyarse en el otro y sostenerse mutuamente. Incluso hemos visto cómo testimonios históricos fueron incorporados a las causas por delitos de lesa humanidad como prueba invirtiendo entonces el peso dado por 
un tipo de testimonios y otros. En el contexto de los juicios, los querellantes aseguran que su relato es veraz toda vez que ya fue requerido por los investigadores "especializados" en el tema.

\section{"La credibilidady la fiabilidad del testimonio: 'Su mantenimiento a lo largo del tiempo"}

Este último componente es probablemente el más complejo y el más polémico entre quienes trabajamos con testimonios orales. Hay quienes sostienen que el mantenimiento del relato en el tiempo, lejos de tornarlo creíble, lo transforma en cuestionable, pues podría ser una mera construcción del militante que repetirá durante años para convencerse que determinadas actuaciones o hechos han sido así, como él o ella lo narran, y no de otra manera. Más aún no solo se trata del sostenimiento del relato a través del tiempo sino también en contextos diferenciados.

Como complemento de este componente cabría entonces agregar la variedad de circunstancias históricas en que se repite el testimonio. Cito entonces un ejemplo de todo lo antes dicho con los relatos de Carlos Soldati. ${ }^{7}$ Soldati vive en la localidad de Simoca, ubicada en el sur de la provincia de Tucumán, en una finca que pertenecía a sus padres. Tiene a dos de sus hermanos secuestrados y desaparecidos, habiendo sido él mismo secuestrado y objeto de torturas. Desde la desaparición de su segundo hermano, en 1977, ha sido un activo militante en tres de los organismos de derechos humanos de la provincia. Los comienzos de su militancia se ubican en Familiares de Detenidos por Razones Políticas, pasando un tiempo por Madres de Plaza de Mayo desde fines de 1981 y finalmente ha sido uno de los fundadores de la Asamblea Permanente por los Derechos Humanos en Tucumán, el 24 de enero de 1984. He podido entrevistar a Carlos a fines de 2007, unos meses antes del primer juicio contra Bussi, en la causa por la desaparición del ex senador Guillermo Vargas Aignase. ${ }^{8}$ Esta entrevista se dio en el contexto de un punto cumbre de las llamadas políticas de derechos humanos de la administración del ex presidente Néstor Kirchner. Como muchos otros activistas del movimiento, Soldati recuerda casi con lujo de detalles las circunstancias del secuestro de su familia, incluidas las de él propio. Los cuatro testimonios que cito en el siguiente cuadro se corresponden, en orden cronológico:

el primero, recogido por el periódico local, data del 12 de febrero de 1984, cuando la APDH local hacía su presentación pública y Carlos narraba su propio secuestro;

el segundo, a instancias de un Juicio Ético contra Bussi el 19 de junio de 1995, donde fungía de testigo y narraba con precisión las mismas instancias de su secuestro;

el tercero de los testimonios se corresponde con la entrevista que le hice el primero de diciembre de 2007 , en su hogar;

el cuarto es el testimonio que prestara Carlos como testigo querellante por su secuestro en el juicio de Jefatura, el 31 de marzo de 2010.
7. La entrevista a Carlos Soldati ha sido realizada el 1 de diciembre de 2007 , días antes de asumir la presidencia de Argentina Cristina Fernández de Kirchner. Por este motivo en varias oportunidades, el entrevistado manifiesta abiertamente cierta esperanza que la continuidad en la línea sucesoria en la conducción política del país lleve a buen término algunos de los procesos judiciales contra los responsables de la dictadura.

8. Juicio que se ha consubstanciado a mediados de 2008 


\section{Los testimonios de Carlos Soldati}

\begin{tabular}{|c|c|c|}
\hline Año del Testimonio & Lugar del Testimonio & Transcripción \\
\hline $\begin{array}{l}12 \text { de febrero de } \\
1984\end{array}$ & $\begin{array}{l}\text { La Gaceta de } \\
\text { Tucumán }\end{array}$ & $\begin{array}{l}\text { «Fui secuestrado en la madrugada del } 28 \text { de septiembre de } 1976 \text { por un grupo } \\
\text { fuertemente armado que irrumpió en la casa de mis padres. Se movilizaban en un auto } \\
\text { y un furgón dentro del cual me arrojaron mientras un camión del ejército supervisaba el } \\
\text { operativo. } \\
\text { (Narró luego que fue trasladado a un campo de concentración cercano a Famaillá) } \\
\text { «Había un considerable número de personas que eran traídas de noche. La tortura era } \\
\text { allí permanente. A la noche siguiente fui trasladado en un camión del Ejército hasta la } \\
\text { brigada de investigaciones, en Avenida Sarmiento y Muñecas, donde funcionaba otro } \\
\text { centro clandestino. Me dieron el número } 102 \ldots\end{array}$ \\
\hline 19 de junio de 1995 & Juicio Ético a Bussi & $\begin{array}{l}\text { El } 28 \text { de septiembre de 1976, a eso de las dos y media de la madrugada un grupo } \\
\text { armado de civil, con la cara cubierta, identificándose como de la policía, entra en la } \\
\text { casa de mis padres, en Manuela Pedraza, cerca de Simoca. La luz se enciende, yo me } \\
\text { siento sobre la cama y los veo subir por la escalera, con armas largas, cortas, linternas, } \\
\text { me preguntan a los gritos por mi nombre, y desde abajo contestan "ese es”... yo estaba } \\
\text { aterrado. “Hay un error, ¿qué pasa, qué pasa?" El que dirigía el grupo, que si estaba } \\
\text { con la cara descubierta y me pone la pistola en la cabeza y me dice que me calle, me } \\
\text { amenaza con matarme, me tira los anteojos y me saca arrastrando de mi casa. Antes } \\
\text { que me pongan la capucha, alcanzo a ver a un auto al frente de mi casa y un poco } \\
\text { más adelante me tiran en el piso y me suben a un camión del ejército, con el sonido } \\
\text { característico de los (...) que supervisaba el operativo. } \\
\text { Cuando me tiran en el piso de la camioneta furgón, veo que hay otra persona ahí tirada. } \\
\text { Tengo la certeza de que ese muchacho era Pedro Pablo Rodríguez, que después me } \\
\text { entero que unos minutos antes había sido secuestrado por el mismo grupo en Simoca. } \\
\text { La camioneta se toma en dirección rumbo al norte a toda velocidad, después de unos } \\
\text { minutos, gira hacia el oeste por el único camino de tierra que conduce hacia Famaillá } \\
\text { y después de unos minutos llego a destino, me bajan y me introducen en lo que es un } \\
\text { corredor ancho y en una galería cerrada me tiran al piso. Pude observar ahí un número } \\
\text { considerable de personas maniatadas, vendadas, que se quejaban. Enseguida gritos, } \\
\text { corridas, ruidos de motores, pregunto qué pasa, "van a buscar más gente”, me dicen (...) }\end{array}$ \\
\hline $\begin{array}{l}1 \text { de diciembre de } \\
2007\end{array}$ & $\begin{array}{l}\text { Entrevista de Historia } \\
\text { Oral }\end{array}$ & $\begin{array}{l}\text { «(...) ese mismo año, el } 28 \text { de septiembre me sacan de esta casa, aquí, de Manuela } \\
\text { Pedraza, un grupo armado, a eso de las dos de la mañana, que se desplazaban en un } \\
\text { vehículo de la policía, ellos se identifican verbalmente como de la policía, estaban de } \\
\text { civil, mis padres estaban aquí, les abren la puerta y bueno... yo duermo en un altillo, } \\
\text { veo que se enciende la luz, me incorporo sobre la cama y los veo subir y a los gritos me } \\
\text { preguntan cómo me llamaba y entonces me sacan arrastrando, me tiran los anteojos, } \\
\text { y... antes de que me colocaran la capucha veo un automóvil de la policía de aquí a 10o } \\
\text { metros, sobre la entrada de la casa y me tiran en el baúl, en el piso de un furgón donde } \\
\text { había otra persona y partimos a gran velocidad. Después un vecino cuando yo aparezco } \\
\text { después, me comenta que un camión del ejército, con el ruido característico de los (...) } \\
\text { que ahí desde la ruta supervisaba el operativo. Y bueno, dicen, una frase: "demasiado } \\
\text { bueno es Videla, ya no quiere más muerte, pero si están en la joda (ese es el término } \\
\text { que usaban) por mucho tiempo no se va a saber de ustedes”.» } \\
\text { Pregunta: ¿Eso les decían a ustedes dos? } \\
\text { «A mí y el otro escuchaba, yo ni sabía quién era. Después me entero, cuando yo } \\
\text { aparezco, de que ese muchacho había sido secuestrado minutos antes, en Simoca, } \\
\text { a cuatro kilómetros de aquí, y era Pedro Pablo Rodríguez. Bueno, yo creí que me } \\
\text { mataban, que me hacían descender del vehículo y me ametrallaban aquí a unos cuantos } \\
\text { kilómetros, pese a que uno está vendado y tirado, pero por el movimiento del cuerpo sé } \\
\text { que el vehículo toma dirección norte y luego de unos minutos dobla hacia la izquierda, } \\
\text { (....) levantan a otro en el camino también, secuestran a otra persona, ya éramos tres y } \\
\text { llego a un lugar que después ubico como Famaillá, pero me bajan como a una especie } \\
\text { de galería cubierta donde había muchas personas, así, vendadas y maniatadas (...)» }\end{array}$ \\
\hline
\end{tabular}




\begin{tabular}{|c|c|c|}
\hline $\begin{array}{l}31 \text { de marzo de } \\
2010\end{array}$ & Juicio de Jefatura & $\begin{array}{l}\text { "El } 28 \text { de septiembre del año 1976, a eso de las dos y media de la madrugada, un grupo } \\
\text { numeroso, entre } 15 \text { y } 20 \text { personas, llegan a la casa de mis padres, en Manuela Pedraza, } \\
\text { cerca de Simoca, “iabran la puerta, es la policía!”, gritan; mi mamá, asustada, les } \\
\text { abre la puerta de la galería del fondo y entran, con armas, con linternas, con la cara } \\
\text { cubierta con medias y pañuelos, se notaba que eran personas jóvenes, menos una, que } \\
\text { actuaba a cara descubierta y con una pistola en la mano, era el que dirigía el grupo, } \\
\text { recorren las habitaciones preguntando dónde está Soldati, el que estudia, de pronto } \\
\text { descubren las escalera del altillo, prenden la luz, el golpe de luz me despierta, me } \\
\text { siento sobre la cama y los veo subir por la escalera. Mientras me alumbraban con sus } \\
\text { linternas, a los gritos me preguntaban cuál era mi nombre y qué hacía, varias veces. } \\
\text { Observo que un muchacho con la cara cubierta con un pañuelo, sube por la escalera, } \\
\text { los otros dicen “ ¿Sabes quién es él? Un asesino profesional contratado para matar”, } \\
\text { desde abajo, el que dirigía el grupo pregunta por mi nombre, le dicen "Carlos Soldati”, } \\
\text { “iEse es!”, yo estaba aterrado. Me pongo a gritar “iHay un error, no puede ser!”, el que } \\
\text { dirigía el grupo sube por la escalera y me pone la pistola en la cara diciendo “Callate } \\
\text { que te mato”, me bajan, y en el living los veo a mis padres contra la pared y los brazos } \\
\text { levantados, nunca pensé verlos de ese modo, como tampoco imaginé ver la casa } \\
\text { familiar avasallada de esa manera. Me toman de los brazos y me sacan a la carrera, } \\
\text { atravesamos el jardín, llegamos al portón chico, veo hacia la izquierda un automóvil, } \\
\text { creo que era un Torino, me tiran los anteojos y seguimos corriendo hacia el portón } \\
\text { grande, donde había un furgón oscuro que estaba esperando. Antes de llegar me tapan } \\
\text { con una capucha, me tiran al piso del furgón y me atan las manos. Me doy cuenta casi } \\
\text { inmediatamente que había otra persona ahí, era Pedro Pablo Rodríguez, que unos } \\
\text { momentos antes había sido secuestrado en Simoca. La camioneta permanece detenida, } \\
\text { esperando (...)” }\end{array}$ \\
\hline
\end{tabular}

La discusión sobre la cuestión de la repetición y la perdurabilidad del testimonio a lo largo del tiempo, como dije, no es nueva y sigue sin ser resuelta. Josefina Cuesta explica que el mantenimiento del relato a lo largo del tiempo es lo que le daría credibilidad y fiabilidad. "Además de la corroboración horizontal, sincrónica, de los otros testigos, el testimonio puede apoyarse en su propia corroboración a través del tiempo, en su permanencia en la diacronía" (Cuesta, 2008: 131). Soldati habla siempre en primera persona; su relato comienza en la experiencia personal del secuestro aunque él ha salido de la detención clandestina y ha recuperado su libertad y salvaguardado su vida, no así sus hermanos que continúan en condición de detenidos - desaparecidos; asimismo en distintos momentos y circunstancias su testimonio se ha mantenido idéntico en el tiempo, casi sin fisuras; es evidente que no sólo fue testigo privilegiado de los hechos que narra sino que él mismo fue víctima del sistema represivo; no busca solo la verdad sino y sobre todo asienta sus expectativas en el principio de justicia; no tiene inconvenientes en transmitir la inquietud de la corroboración de su testimonio; guarda consigo una carpeta de recortes de prensa como modo de afirmar, materialmente, su memoria.

En todo caso resulta conveniente el entrecruzamiento de fuentes, el contrastar todos los relatos y buscar la correlación entre lo que se dice y lo que suponemos realmente ocurrió, en los términos planteados por Alessandro Portelli. No implica por tanto quedarnos con aquello que se presenta repetitivo en ciertos relatos, sino en la búsqueda por encontrar los puntos de veracidad y credibilidad en los mismos, por indagar sus rupturas como así también las contradicciones internas que hacen al testimonio, por un lado, y a la apreciación personal y subjetiva que de los acontecimientos vividos tienen los sujetos sociales, percepción que no siempre es lineal aunque el investigador procure encontrar la coherencia interna del relato narrado. Insisto aquí que lo complejo en este tipo de trabajos es el atravesamiento de las múltiples realidades que vive el testigo y que lo convierte en un protagonista tanto del pasado como del presente y mucho más aun de la interpretación de ambos tiempos históricos. 


\section{Consideraciones finales}

Renaud Dulong establecía las diferencias entre el testimonio judicial y el testimonio histórico:

...durante la declaración delante de los tribunales, al testigo judicial se le exige que "se atenga a los hechos"; el testigo histórico, por su parte, tiene por misión transmitir una experiencia límite, de hacer comprender el sufrimiento, la humillación, la repugnancia, la obsesión por la muerte y la voluntad de sobrevivir. Éste ha de hacer públicos detalladamente los tormentos que han dejado marca en su cuerpo y que han hecho bascular su concepción del mundo. Así, el testimonio debe provocar en quien lo recibe una reacción afectiva, un juicio de valor, un sentimiento que se pueda explicitar con un "esto nunca más" (Dulong, 2004: 1-2).

Existe en todo caso un compromiso ético tanto en el testimonio histórico como en el testimonio judicial: del primero emanará el principio de la verdad, del segundo el de la justicia y ambos deben ser complementarios y a los dos los asiste la memoria. Es la demanda histórica del movimiento de derechos humanos en Argentina: la memoria, la verdad y la justicia.

Dulong reflexiona entonces:

Si tal es la función de estos relatos autobiográficos, entonces plantean un problema de pragmática literaria: ¿cómo pueden llegar a conmover al lector y movilizarlo? No basta con que la intención de testimoniar presida su escritura. Sabemos que, entre un gran número de escritos sobre los campos nazis, sólo algunos han conocido una recepción suficientemente amplia para que se pueda hablar de éxito-menos de notoriedad literaria que de la transmisión de un mensaje sobre la realidad-. Hay pues unas «condiciones de éxito» del testimonio sobre el horror: es preciso que el texto pueda ser leído por un público numeroso, que responda a las exigencias de autenticidad de un testimonio, etc. Aquí me interesaré por una condición menos evidente: el dispositivo de escritura debe poner en juego una dimensión capaz de desatar la indignación del lector; esta dimensión está directamente articulada con el cuerpo del testigo (Dulong, 2004: 1-2).

Dicho en otros términos, hacer historia oral y entrevistar a militantes que han sido fundamentales en el devenir de la historia reciente y que aún continúan actuando en la historia presente, debe tener entonces un imperativo moral y ético. El presente de los entrevistados que aún militan en el campo de los DDHH no testimonian sólo por "recordar" qué ha sucedido, qué han creído ellos que sucedió o qué quisieron que sucediera, sino que relatan su historia con la expectativa que con su narración el principio de verdad y justicia se vean cumplidos. Quienes nos dedicamos a estudiar estos temas pensamos que nuestras investigaciones deben servir para contribuir con el tan declamado Nunca más a pesar de ir a contracorriente no solo de la historiografía tradicional sino y sobre todo, del pensamiento conservador que aún parece ser el hegemónico. 


\section{O Bibliografía}

"Camarena, M. y Necoechea G. (2008). "Continuidad, ruptura y ciclo en la historia oral”, en Pozzi, P. y Necoechea, G. (comps.). Cuéntame cómo fue. Buenos Aires: Imago Mundi.

»Carnovale, V. Lorenz, F. y Pittaluga, R. (comps). (2006). Historia, Memoria y Fuentes Orales. Buenos Aires: CEDINCl.

»Cuesta, J. (2008). La odisea de la memoria. Historia de la memoria de España, S. XX. Madrid: Alianza Editorial.

»Dulong, R. (2004). "La implicación de la sensibilidad corporal en el testimonio histórico". Revista de Antropología Social (Universidad Complutense de Madrid), 13 .

» García Orellán, R. (2012). “De la oralidad a la intención biográfica”, en Llona Miren (coord.,/ ed.). Entreverse. Teoría y metodología práctica de las fuentes orales. Bilbao: UPV.

》 Hobsbawm, E. (1998). Sobre la Historia. Barcelona: Crítica.

»Kotler, R. (2018). Huellas de la Memoria en la Resistencia Antibussista. Historia del movimiento de Derechos Humanos de Tucumán. Buenos Aires: Imago Mundi.

»LaCapra, D. (2005). Escribir la historia, escribir el trauma. Buenos Aires: Nueva Visión.

"Portelli, A. (1991). "Lo que hace diferente a la historia oral”, en Schwarzstein, D. (comp.). La Historia Oral. Buenos Aires: Centro Editor de América Latina.

»Thompson, P. (1998). La voz del pasado. Historia Oral. Valencia: Ediciones Alfons el Magnánim.

»Vezzetti, H. (2000). “Un Mapa por trazar”. Revista Puentes, 1.

»Williams, R. (2009). Marxismo y Literatura. Buenos Aires: Las Cuarenta. 
